\title{
La barrera entre el periodista y el documentalista
}

\author{
Cristina BARANDA DEL CAMPO \\ Doctora en Ciencias de la Información \\ Universidad Complutense de Madrid \\ cbcb.rm@gmail.com
}

Recibido: $13 / 03 / 2012$

Aceptado: 10/04/2012

\section{RESUMEN}

El documentalista de información es el especialista capaz de documentar a los profesionales de la comunicación inmersos en el laberinto de las nuevas tecnologías. Su formación debe ir acorde a ese avance tecnológico y al vertiginoso acontecer de la actualidad. Este artículo de investigación trata de averiguar si existe barrera entre periodistas y documentalistas, o por el contrario un espacio común de trabajo en el que colaboran todos. Ambas profesiones son fundamentales en la Sociedad, y mientras haya información habrá periodistas y documentalistas trabajando por ordenarla, elaborarla, tratarla, gestionarla y servirla a los usuarios. Es posible que exista una frontera entre ellos, como se va a desarrollar en este artículo, pero en esa franja de separación, existen numerosos intervalos de tiempo y zonas comunes entre los profesionales de la comunicación.

Palabras clave: periodista, narrador, gestor de contenidos, documentalista de información, barrera, frontera, espacio común de trabajo, fusión, formación, documentalista de información de actualidad.

\section{The barrier between journalist and documentary}

\begin{abstract}
Documentary information is the specialist able to document communication professionals involved in the maze of new technologies. Your training must be commensurate with the rapid technological advances and current events. This research paper seeks to ascertain whether there are barriers between journalists and librarians, or otherwise work a common space with the collaboration of all. Both professions are essential to the Company, and while there will be journalists and documentary information work in order, process, treat, manage and serve it to users. There may be a border between them, as will develop in this article, but in this age of separation, there are several time intervals and areas between media professionals.
\end{abstract}

Keywords: journalist, novelist, content manager, documentary information, barrier, border, common working space, fusion, training, current awareness documentary. 


\section{INTRODUCCIÓN}

Por un lado como dice la periodista y escritora Deborah Potter en su Manual de Periodismo Independiente ${ }^{1}$ el Periodismo es: a la vez una profesión y un arte, pues los periodistas aplican habilidades especializadas y se someten a normas en común. La mayor diferencia de otras ocupaciones es quizá el papel especial que los medios informativos, desempeñan en una sociedad libre. De esta manera el propósito primordial del periodismo es suministrar a los ciudadanos la información que necesitan para desplegarse en una sociedad independiente.

Por otra parte como afirma el profesor Roberto Coll Vinent ${ }^{2}$ : el objetivo básico de la Documentación reside en la recuperación rápida y segura de toda suerte de informaciones y...contempla la necesidad del usuario del potencial de información y las posibilidades técnicas de satisfacer ampliamente esta necesidad. Para ello el objetivo de cualquier documentalista es realizar la mejor y más eficiente gestión con la información. Pero antes de la rapidez informativa está la veracidad y el rigor informativo, pilares necesarios para una gestión adecuada de la información.

El periodista y el documentalista son dos profesionales diferentes con una formación distinta y paralela, pero con muchos puntos de contacto en sus trabajos. Con el fin de realizar un análisis de los ámbitos de trabajo de estos profesionales se ha utilizado como punto de referencia la intervención del profesor Rafael Díaz Arias en el Seminario de Documentación en los Medios de Comunicación, del Departamento de Biblioteconomía y Documentación de la Facultad Ciencias de la Información: “ ¿Periodistas?, ¿Documentalistas? Lo importante es el mensaje”, el 11 diciembre 2007.

En cuanto al papel de los periodistas en la era digital se ha trabajado con el Proyecto para la Excelencia en Periodismo de Tom Rosenstiel en 2005. Se ha investigado, posteriormente, los límites de sus profesiones y si existe o no barrera entre ellos a partir del artículo de Vicent Partal i Montesinos: "Periodistas y Documentalistas, ¿Dónde está la frontera?”. Se ha trabajado a continuación en los ámbitos de labor de periodistas y documentalistas, en el análisis de sus funciones, el intercambio de papeles y las nuevas relaciones que han surgido entre la redacción y el archivo, para todo ello ha servido de base el trabajo de los profesores José A. García Avilés, Pere Masip Masip y Josep Lluís Micó Sanz: "Redefinición del perfil y funciones del documentalista en las redacciones digitales de medios españoles" y "Periodistas que ejercen de documentalistas ( ¿y viceversa?). Nuevas relaciones entre la redacción y el archivo".

\footnotetext{
${ }^{1}$ POTTER, Deborah: "Manual de Periodismo Independiente".

www.scribd.com/doc/24972790/Manual-de-Periodismo-independiente-by-Deborah-Potter (consultada agosto 2010)

${ }^{2}$ COLL VINENT, Roberto: “CIENCIA DOCUMENTAL: Principios y sistemas”. Barcelona, Mitre, 1984.
} 
Se ha estudiado el perfil del documentalista y sus funciones a partir del compendio elaborado sobre esta figura por los Drs. López Yepes y Ros García: “¿Qué es Documentación? basado en investigadores que la han estudiado. Del mismo modo ha servido de fundamento para el análisis del profesional de la Documentación la tesis doctoral del Dr. Del Valle Gastaminza: "El profesional de la Documentación. Perfil histórico y formación Académica". Y la obra de la Doctora Rubio Lacoba: "El perfil triangular del documentalista digital: novedades y constantes del emisor de documentación en el periodismo digital". Para analizar la vinculación del periodismo de precisión y la documentación informativa, y las labores que comparten estos profesionales, se ha estudiado la obra del Dr. Aquesolo Vegas: "De la documentación informativa al periodismo de precisión". De igual modo para fundamentar la aproximación de los perfiles formativo e investigador de los profesionales de la información ha servido de referencia la conferencia del Dr. Antonio García Gutiérrez: "Notas sobre procesos reflexivos y funciones en los nuevos especialistas de información: aproximación a los perfiles formativo e investigador". Se ha trabajado en el estudio de los nuevos estándares de redacción para la prensa digital y los criterios para su organización y redacción de las informaciones periodísticas en Internet y la recuperación de elementos básicos de escrito: narración, descripción, exposición, y argumentación, a partir de los trabajos del profesor Ramón Salaverría: "De la pirámide invertida al hipertexto" y "Periodismo Integrado" junto al profesor Samuel Negredo.

En el último epígrafe de este artículo se analiza la figura del documentalista de información de actualidad y se termina concluyendo sobre todo lo tratado en el mismo. La sociedad avanza y los medios van evolucionando al mismo tiempo que la tecnología. Surgen nuevas herramientas derivadas de estos avances. Se trata de ofrecer el modelo de formación óptimo para el documentalista de información, a partir del estudio de sus competencias para, a partir de ellas, diseñarla. Y siguiendo el trabajo del Dr. Carlos M. Tejada Artigas: : "El debate de la formación universitaria en ByD: más allá de Bolonia", se ha analizado la posibilidad de que en los próximos años desaparezca el Grado en Información y Documentación, pasando la formación a un máster de especialización. Los posgrados tendrán que tener una formación no sólo basada en la Biblioteconomía, Documentación y Archivística, sino conjunta con otras disciplinas.

\section{EL PERIODISTA, NARRADOR DE INFORMACIONES}

El periodista se encuentra ante una gran paradoja: la crisis y la regeneración, pero hasta ahora nunca se ha encontrado con unas herramientas tan útiles para ejercer su profesión. Su papel de seguidor de las noticias aplicando valores de verdad, lealtad al lector, verificación independiente de hechos y personas, derecho a ejercer lo que le dicta su conciencia, independencia respecto a cualquier poder establecido, convertir 
lo importante en algo interesante, no han de cambiar nunca trabaje en el medio en que trabaje y evolucionen las tecnologías lo que evolucionen.

El mundo del Periodismo sufre cambios bruscos. No es que haya seguido una evolución sino más bien una revolución. El tratamiento de la complejidad es decisivo. Hasta ahora el periodista ha transformado los elementos complejos con el fin de que la gente los entendiera. Ahora sucede al revés, el periodista realza la complejidad. El periodista ya no explica la realidad, sino que la vigila y trata de situarla. Como afirma Vicent Partal: "El periodista es el cartógrafo de la información" ${ }^{3}$

La imagen ha venido a describir el paso entre el periodista narrador y el periodista situador. En los periódicos tradicionales, radios y televisiones el trabajo de gestionar la complejidad la hace el documentalista. La profesión de periodista es un poco antigua, desde hace doscientos años el objetivo ha cambiado poco. Se va a un sitio, se ve lo que sucede, se intenta explicar de una manera coherente, bien escrita, fácil de entender y ya está. Pero el mundo ha cambiado mucho en estos años, especialmente en los últimos treinta años. El trabajo del periodista se ha transformado. Aunque el periodista tradicional sigue siendo pieza clave, porque los medios tradicionales siguen siendo los medios poderosos. El inicio del cambio ya está marcado y viene dado, sobre todo, por el concepto de la complejidad.

Las grandes revoluciones siempre las intuyen los artistas, más tarde se produce un hecho científico que suele consolidarles y, finalmente siempre llega la política con la economía detrás. Los artistas dicen: "no, la realidad existe fuera de nosotros, la realidad la convertimos nosotros porque depende de nuestra interpretación". Y política y comunicación siempre van ligadas. En 1974 hay una revolución tecnológica sin precedentes. En 1984 surge el primer ordenador personal. Y en 1991 aparece la Web. Súbitamente internet sirve para todo. El usuario siempre elige. La persona es quien decide la información que desea mirar. El poder pasa de estar en manos de quien emite a estar en manos de quien recibe. El periodista deja de ser el transmisor de la realidad, las fuentes ya son públicas.

El nuevo modelo de comunicación basado en Internet hace que el modelo tradicional se estanque. Este sistema de comunicación en red entre iguales será tan importante que casi ningún elemento del pasado podrá permanecer en su sitio. Los medios de comunicación se sostienen así hoy, porque son pocos y caros. Unos cuantos que tienen intereses muy específicos los pagan. La efectividad de los medios profesionales les hace posible resaltar y destacar unos hechos determinados. Durante cada jornada pasan muchas cosas, pero las que nos afectan casi no aparecen.

${ }^{3}$ PARTAL I MONTESINOS, Vicent: Periodistas y Documentalistas, ¿Dónde está la frontera?.2002. www.uoc.edu/web/esp/art/uoc/partal0402/partal0402.html (consultada marzo 2010) 
El receptor tiene una actitud muy activa en el nuevo sistema de comunicación. La persona decide la información que desea. El poder pasa de estar en manos de quien emite a estar en manos de quien recibe. Internet nos permite mirar todas las partes posibles. Además la gente puede publicar. Nadie puede imponer una teoría, nadie puede imponer una imagen de la realidad. La sociedad es compleja, pero queremos información simple que no quiere decir sencilla. El nuevo modelo de información tiene un esfuerzo para nosotros, nos hace partícipes ya que debemos capturar la información y procesarla. No tenemos porque aceptar, ya, la información que nos da alguien, debemos buscar la realidad de esa información para entender que todas sus versiones tienen un poquito de razón. Somos libres de elegir la parte de razón de cada uno y la posición que se adopta.

Lo ideal sería la alternancia del modelo nuevo de comunicación con el sistema tradicional. Habrá muchos momentos en el día que nos guste ser receptores pasivos y no estar eligiendo continuamente y no decidir sobre la información. En cambio habrá algunos temas que nos interesen mucho y busquemos más información. Internet tiene una característica que le diferencia de otros medios y es el enlace y éste es la esencia del mismo.

Este es el nuevo periodismo, sumergirse en una realidad e intentar explicar a la gente que tiene muchos puntos desde los cuales conseguir la información que necesita, si esa información le interesa. El periodista narrador de informaciones y acontecimientos se convierte en gestor de la información gracias a la nueva tecnología, encabezada por Internet.

\section{EL DOCUMENTALISTA, GESTOR DE CONTENIDOS}

El profesor Félix del Valle Gastaminza define al documentalista como: "la persona que analiza y gestiona información con herramientas y criterios profesionales" ${ }^{4}$. Entre sus funciones destacan la de controlar el universo informativo, la de seleccionar la información más adecuada a las necesidades de los usuarios, valorando el coste y el rendimiento que tendrán para ellos y la de dar a la información un valor añadido a través de su control y tratamiento, facilitando que los usuarios puedan recuperarla y utilizarla eficaz y ordenadamente.

Según el pensamiento general los periodistas tienen fama de desordenados. El documentalista está mucho más acostumbrado a ordenar las cosas, a comprobar cuál es el origen real de una frase, de una palabra, de un texto, de un contexto. Pero existen unas funciones del documentalista que permanecen siempre, a pesar del avance de las

${ }^{4}$ DEL VALLE GASTAMINZA, FÉLIX: Tesauros e Información Audiovisual: estudio de caso. Documentación de las Ciencias de la Información; 2003; ISSN: 0210-4210, nº 26; pp. 165-180. 
tecnologías y de los papeles cambiantes de los profesionales de la comunicación, como la función selectiva y valorativa de la información con un sentido crítico, que a veces el gran número de fuentes de información dificulta llevarlas a cabo. Otra función del documentalista de información que resurge es la de gestión de contenidos. Si quiere controlar el aluvión de informaciones que le viene de Internet, ha de evaluar la información del conocimiento de sus usuarios, organizándola, controlándola e indicando al periodista dónde puede encontrarla. La Dra. María Rubio Lacoba afirma al respecto: "la capacidad gestora exige un alto grado de confianza en el servicio de documentación" para gestionar la información y como tales se ha de confiar en ellos, para que puedan suministrar ordenada y rápidamente la información más adecuada a periodistas y usuarios.

Las tecnologías de las comunicaciones y de la información están facilitando el surgimiento de casos de intercambio de papeles entre profesionales de la información hasta ahora muy extraños. Muchos informáticos se han convertido en productores de información a partir de la explotación de bases de datos. Bastantes periodistas se han transformado en excelentes documentalistas y numerosos documentalistas en buenos gestores del conocimiento. Hace una década, este fenómeno ya lo apuntaban los profesores A. Pérez Hernández y D. Rodríguez Mateos: "las tecnologías de la información y de las comunicaciones (TIC) están propiciando la aparición de fenómenos de convergencia entre profesionales hasta ahora muy diferentes"

\section{FUSIÓN DE AMBOS PROFESIONALES}

Los periodistas tienen cada vez más necesidad de las herramientas de los documentalistas y de entender su tradición, que sea llevada a las empresas y que evolucione de la mano del periodismo. Según Vicent Partal: "Los periodistas debemos aportar nuestras tradiciones al nuevo mundo con humildad, reconociendo que ya no somos los amos, que somos uno más, que podemos aportar nuestros conocimientos con gracia y ayudar a que todo evolucione de una manera más racional....los documentalistas tenéis el mismo reto, aportar aquellas partes de vuestra tradición que

${ }^{5}$ RUBIO LACOBA, MARÍA: “ Nuevos tiempos para la documentación informativa en el periodismo digital: viejas y nuevas funciones del servicio de documentación digital". Universidad de Navarra. Comunicación y Sociedad. Volumen XVIII, nº 1, junio 2005.

www.unav.es/cys/xviii1/proteger/rubio.html (consultada mayo 2010)

${ }^{6}$ HERNÁNDEZ PÉREZ, A. y RODRÍGUEZ MATEOS, D.: "Las nuevas competencias del profesional de la información: del control de documentos a la gestión del conocimiento". Jornadas Españolas de Documentación, Vol. 7, 2000. 
pueden servirnos para mejorar y entre todos construir este nuevo modelo informativo que tiene una gran fuerza”.

Antes apuntaba que el enlace es la esencia de Internet. Lo importante es que alguien articule al usuario un conjunto coherente de enlaces, esta labor la hacen los documentalistas. Pero en la realidad diaria lo hacen los periodistas. La barrera que existía entre ambos profesionales es que los documentalistas se encargaban de la información cuando ya había pasado, mientras que los periodistas intentaban situar el acontecimiento cuando la noticia estaba ocurriendo o finalizando.

El futuro de la documentación informativa está en la anticipación del evento periodístico futuro, producto que necesita una cuidada elaboración periodística y documental también está en el uso y organización de la información en los nuevos medios. En los procesos de digitalización de la información audiovisual, el papel del documentalista se realza. Rafael Díaz Arias, en su intervención en el I Seminario de Documentación en los Medios de Comunicación, Departamento de Biblioteconomía y Documentación de la Facultad de Ciencias de la Información, 11 diciembre 2007 afirmaba: "Los periodistas tendrán que ser cada vez más capaces de recuperar y gestionar información, pero siempre necesitarán del documentalista, convertido ahora en gestor de información digital y que tendrá que tener en cuenta el uso y finalidad periodística de esa información". ${ }^{8}$

A veces, periodistas y documentalistas se enfrentan por pensar que uno es independiente del otro, que un documentalista no necesita al periodista y viceversa. En la realidad las dos disciplinas se complementan porque lo que cuenta es el trabajo realizado y la información que se va a emitir.

En cuanto al papel de los periodistas en la era digital Tom Rosenstiel, director del Proyecto para la Excelencia en Periodismo, mantiene que el periodismo está dejando de ser un producto para convertirse en un servicio, y de ahí que esté dejando de ser un destino final para convertirse en parte de una red. Rosenstiel destaca estas cuatro funciones posibles de un periodista: “Autenticador, Generador de sentido, Navegante y Animador de la conversación".. Son funciones que ayudan a la audiencia a decidir qué creer, a darle sentido a lo que está pasando alrededor, a seguir una historia encaminándola hacia la información más interesante y a mantener una discusión con argumentos. Los periodistas han de estar muy cerca de sus lectores, tanto de los de periódicos de papel como de los de la red, y saber lo que quieren y entenderles, han de

${ }^{7}$ PARTAL I MONTESINOS, Vicent: Periodistas y Documentalistas, ¿Dónde está la frontera?.2002. www.uoc.edu/web/esp/art/uoc/partal0402/partal0402.html (consultada marzo 2010)

${ }^{8}$ DÍAZ ARIAS, R. (2007): “¿Periodistas?, ¿Documentalistas? Lo importante es el mensaje”. Intervención, 11 diciembre 2007, Seminario de Documentación en los Medios de Comunicación, Departamento de Biblioteconomía y Documentación Facultad Ciencias de la Información.

${ }^{9}$ ROSENSTIEL, TOM. Proyecto para la Excelencia en Periodismo. 2005 
dar sentido a sus informaciones, ya que ahora los usuarios demandan otro tipo de informaciones y solo entendiendo sus aspiraciones se puede animar la conversación y hacer realmente un producto informativo capaz de satisfacerles.

En la última década el periodismo ha sufrido grandes cambios. El usuario se siente protagonista en la red y participa de igual a igual. El nivel de competencia es máximo. Al ser un canal de comunicación abierto, cualquiera puede participar y surge la rivalidad por ver quién lo hace mejor, su comentario es el más interesante o su aportación es la más novedosa.

El periodista actualmente se preocupa por el hecho de que su información esté bien distribuida, sea vista y leída por el mayor número de lectores y produzca un elevado nivel de participación. Estas mediciones mantienen el nivel de competencia al máximo, y el futuro de cada periodista depende en buena medida de ellos. Por este motivo, la exigencia de la calidad va en aumento. Esas trabas físicas ahora han desaparecido. La red distribuye las informaciones por todas partes en menor tiempo, distancia y espacio físico. Cada movimiento de un periodista en la red es una manera de hacer la distribución de una noticia determinada, bajo el formato que sea. La información fluye por todas partes y los RSS son ofrecidos de múltiples maneras sin necesidad de buscarlos. Se sirve la información a la carta. Gracias a la cartografía digital se ofrece un valor añadido a la información y una calidad en la misma, con el fin de maximizar el uso efectivo de los sistemas de información. Sin el conocimiento de las distintas bases de datos se tienen menos oportunidades.

Tan sencillo como meter unos datos en un buscador y hacer clic, es de rápida la aparición de la noticia o la información. Y de esa aparición a otros enlaces con sucesivos clics y sus consiguiente apariciones de información.

Paul Bradshaw sostiene que: "Una de las principales habilidades para cualquier periodista en la edad de los nuevos medios de comunicación, con independencia del soporte en el que esté trabajando, es su capacidad de adaptación argumentando su familiarización con las nuevas tecnologías". ${ }^{10}$ en efecto, si se observa cualquier medio de comunicación en la actualidad lo primero que se percibe es la presencia de las nuevas tecnologías, por esta razón el mercado laboral está cambiando y se buscan perfiles profesionales que se hagan cargo del proceso de convergencia que viven las empresas de estos medios. Como dice el Dr. Orihuela Colliva: "Ya no se buscan especialistas en medio, son especialistas en temas con capacidad de plasmarlos en diversas plataformas tanto de viejos como de nuevos medios. Gente versátil, con gran capacidad para aprender, para reinventarse y para innovar" 11

\footnotetext{
${ }^{10}$ BRADSHAW, PAUL. Press Gazette. 2007

http://www.pressgazette.co.uk/story.asp?storycode $=40263$ (consultada julio 2010)

${ }^{11}$ ORIHUELA COLLIVA, J.L.: Entrevista, 23 mayo 2007, por Stephanie Falla Aroche en Maestros del Web.
} 
El periodista y el documentalista han vivido la revolución tecnológica y han visto la necesidad de adaptarse a los nuevos medios y a la velocidad de producir información y de organizar y gestionar documentación. Ambos profesionales son necesarios y sus trabajos se complementan y sus figuras se funden en muchas ocasiones. Unos como otros han de colaborar y avanzar adaptándose a las nuevas tecnologías.

En el ámbito de medios de comunicación el mercado laboral, está cambiando y se exigen nuevos requisitos profesionales, así lo afirma el profesor José Luis Orihuela Colliva:"Se verifica la búsqueda de perfiles profesionales que puedan hacerse cargo del gran proceso de convergencia que están viviendo las empresas de medios. Ya no se buscan especialistas en medios, sino especialistas en temas con capacidad de plasmarlos en diversas plataformas tanto de viejos como de nuevos medios. Gente versátil, con gran capacidad para aprender, para reinventarse y para innovar". ${ }^{12}$

El profesor Ramón Salaverría propone el empleo de los tipos básicos de escrito, narración, descripción, exposición y argumentación, como nuevo criterio para organizar y redactar las informaciones periodísticas en Internet: "Estos nuevos modos de estructurar la información en entornos hipertextuales vienen de la recuperación de unos elementos menos preciados durante años por los periodistas, los tipos básicos de escrito o modalidades básicas de enunciación: la narración, la descripción, la exposición y la argumentación”. ${ }^{13}$ Está claro que las características hipertextuales del nuevo medio reclaman estándares redaccionales renovados que faciliten la descomposición de los textos periodísticos en unidades plenas de sentido. La noticia ya no sería una estructura cerrada, sino un conjunto de elementos interconectados mediante el hipertexto y cuyas partes vendrían marcadas por el acontecimiento informativo comunicado en cada caso. De este modo, el uso de los tipos básicos de escrito facilita una manera útil para que los periodistas actualicen su profesión en el nuevo campo de la prensa digital.

Para dominar todos estos aspectos "hay que conocer el medio y su lenguaje, no sólo las herramientas y los códigos para construirlo. Hay que entender a la gente y sus peculiares modos de acceder y consumir información online, no sólo diseñar para los colegas. Hay que tener vida y fuentes fuera de la web, para que la vida y

${ }^{12}$ ORIHUELA COLLIVA, JOSÉ LUIS: Entrevista 23 mayo 2007 por Stephanie Falla Aroche en Maestros del Web.

${ }^{13}$ SALAVERRÍA, RAMÓN. De la pirámide invertida al hipertexto. Hacia nuevos estándares de redacción para la prensa digital”. Publicado en NOVÁTICA (revista Asociación de Técnicos Informática), vol. 142, nov.-dic. 1999, pp. 12-15. 
las fuentes que tenemos en la Web, no queden desconectadas del mundo real"14, según señala el profesor Orihuela.

Cuando el profesional de la información es consciente de lo que demanda la audiencia y domina medio, lenguaje y herramientas debe estar bien documentado. La digitalización de los archivos de los medios de comunicación ha permitido mejorar tanto el trabajo de los documentalistas como el de los periodistas. Sin embargo, muchos redactores españoles prefieren buscar información en Internet antes que en los nuevos servicios de documentación. Los doctores Josep-Lluís Micó-Sanz, Pere Masip-Masip y José Alberto García Avilés afirman, tras una reciente investigación sobre como la tecnología transforma las prácticas periodísticas, que: "el hecho de que muy pocos periodistas cuenten con la formación adecuada para la recuperación de datos es la causa de que la calidad de sus producciones vaya en descenso ${ }^{15}$. Debido al uso de Internet, aunque no sólo por ello, "Los periodistas han adquirido mayor protagonismo en la búsqueda y recuperación de la información, llegando a modificar sus rutinas, y su relación con los documentalistas" $"$.

La digitalización abre nuevas vías en el análisis de las competencias profesionales en los medios. Muchas empresas implantan algún tipo de conexión para crear un marco común: la redacción multimedia, una fábrica informativa que reúne mensajes, gestiona y canaliza trabajo para editar las versiones impresas, audiovisuales y en línea de contenidos cada vez más personalizados.

La convergencia de funciones y los nuevos perfiles llevan a la desaparición o cambio de ciertos roles profesionales. Es necesario reflexionar sobre ambas profesiones, periodismo y documentación, en el momento actual y dar una visión de futuro en las titulaciones y en la delimitación de las tareas específicas que han de desempeñar.

Hoy por hoy, la ciencia de la información y la ciencia de la comunicación, son profesiones distintas con titulaciones diferentes, aunque comparten intereses comunes. El fin del comunicador no es ordenar la información, como el fin del documentalista no es crear nueva información. Pero ambas profesiones están en el mundo de la información y es importante establecer relaciones desde el punto de vista de la colaboración.

${ }^{14}$ ORIHUELA COLLIVA, J.L.: Entrevista 23 mayo 2007 por Stephanie Falla Aroche en Maestros del Web.

${ }^{15}$ MICÓ-SANZ, JOSEP-LLUÍS; MASIP-MASIP, PERE Y GARCÍA-AVILÉS, JOSÉ ALBERTO: EPI, mayo 2009, pp.284-290. "Periodistas que ejercen de documentalistas (¿y viceversa?). Nuevas relaciones entre la redacción y el archivo".

${ }^{16}$ MICÓ-SANZ, JOSEP-LLUÍS; MASIP-MASIP, PERE Y GARCÍA-AVILÉS, JOSÉ ALBERTO: EPI, mayo 2009, pp.284-290. "Periodistas que ejercen de documentalistas (¿y viceversa?). Nuevas relaciones entre la redacción y el archivo". 
En la actualidad se produce cierta identificación entre periodista y bibliotecario por similitudes en la situación profesional. Va desde el arraigo de algunos periodistas al papel, ignorando las tecnologías hasta los temores y la crisis de identidad que les supone el surgimiento de todo lo que se engloba bajo el cartel de la Web 2.0. Ahora cualquiera puede expresar su opinión ante un público de una manera sencilla. El cúmulo de información que navega que nos llega a diario es tal, que siempre hará falta alguien que la filtre y que consiga que lo que llega al usuario es lo que realmente necesita, para que no pierda el tiempo en tonterías y que pueda utilizar esa información para crearse una opinión y usarla críticamente. Sería la alfabetización en la información, cuestión que ya se planteaban los bibliotecarios desde hace tiempo (ALFIN) ${ }^{17}$. Periodistas y Bibliotecarios, son dos colectivos que trabajan en lo mismo, de forma paralela, sin ninguna colaboración entre ellos.

En las redacciones es donde se está librando la batalla del futuro de los medios de comunicación y del negociado de la información. Cuando el profesor Juan Carlos Marcos Recio habla del Documentalista de Información Electrónica resalta la apuesta de la documentación por hallarse al mismo nivel que la información: "Ante la constante presencia de nuevos soportes en el periodismo electrónico, la documentación ha apostado por estar presente al mismo nivel que la información..." ${ }^{18}$ para lo cual, el documentalista no puede estancarse en una formación arcaica, en una disciplina estática y antigua, ha de evolucionar de la mano de la formación del periodista, conociendo los medios y las tecnologías utilizadas por éstos. De su evolución depende el perfil del periodismo y la ocasión de reconvertir la organización de las empresas periodísticas en empresas modernas del siglo XXI. El periodista adopta nuevos perfiles. Evoluciona hacia un periodismo integrado. Según afirman los profesores Ramón Salaverría y Samuel Negredo: "Aunque sus esencias permanecen, cambian conceptos, evolucionan procedimientos y mudan lenguajes. El periodista que trabaja en los nuevos grupos multiplataforma debe tomar conciencia del entorno y adaptar su perfil profesional, entendiendo las reglas de la nueva relación con el público, anticipándose a los cambios que se imponen en la estructura interna e interiorizando las claves de la edición multiplataforma" $"$. A pesar de ello nunca debe perder su rol más importante: el de comunicador.

Pero si el periodista hace de documentalista y el documentalista hace de periodista, todas las tareas del profesional de la información: selectiva, valorativa, de recuperación, gestora y difusora, cobrarán su sentido pleno siempre que pasen por la capaci-

\footnotetext{
${ }^{17}$ Alfabetización Informacional, tipología de información.

${ }^{18}$ MARCOS RECIO, JUAN CARLOS: El Documentalista de Información Electrónica. Documentación de las Ciencias de la Información, 19. pp. 193-210. ISSN 0210-4210. Madrid, 1996.

${ }^{19}$ SALAVERRÍA, R. Y NEGREDO, S. "Periodismo Integrado". Barcelona, Sol.90.Media, 2008. ISBN: 978-84-9820954-9; pp. 151-181.
} 
dad de coordinación del documentalista con el periodista. Como bien afirma la profesora María Rubio Lacoba: "Cuanto mayor sea el flujo de comunicación entre estos profesionales, que intercambian tareas en algunos casos, mejor será la calidad de sus trabajos, puesto que los perfiles no se superpondrán y las actividades serán cooperativas y no conflictivas "20. Mientras exista la información las tareas de ambos, periodistas y documentalistas de información, serán necesarias.

\section{EL DOCUMENTALISTA DE INFORMACIÓN DE ACTUALIDAD}

Mucho se lleva debatiendo en torno a la formación universitaria en Biblioteconomía y Documentación. La Dra. Belén Fernández Fuentes, de la Universidad Complutense de Madrid, considera: "discutible que a estas alturas sea la misma carrera la de biblioteconomía que la de documentación... son profesionales distintos, con diversas funciones y por tanto merecen diversa preparación". Al principio se cuestionaba su necesidad, después se asentó su formación en toda España. Ahora se reflexiona por el proceso de Bolonia. No sólo por reglar los estudios con toda Europa, sino por la propia existencia de los mismos. Por otra parte, los profesionales recién titulados optan a un primer empleo en el que no se les reconoce su condición como tales y se les emplea como técnicos.

El documentalista no se ha de contentar con prepararse solo para las bibliotecas, centros de documentación y archivos ha de ampliar sus miras y formarse también como gestor de información. Si está preparado para un abanico más amplio de oportunidades, su formación ha de abarcar más materias y diversificarse más. De este modo se irá haciendo más imprescindible y la sombra de que estas disciplinas puedan desaparecer irá difuminándose.

$\mathrm{Se}$ ha de formar en nuevas tecnologías de un modo más completo y exhaustivo. Su formación en informática ha de superar el nivel de usuario. Debe alcanzar unas destrezas tecnológicas que le permitan ser independiente y no un mero interlocutor de los informáticos. Actualmente con los grados, con una duración en créditos igual para todas las titulaciones, esta disciplina se ve reforzada y con mayor competencia. La imagen social de la carrera ha de experimentar, también, notables mejoras, pues esto condiciona el número de alumnos que escogen la carrera. Eligen menos alumnos Documentación porque tienen menos salidas y están muy poco valoradas socialmente. El Dr. Carlos Tejada afirmaba al respecto: "ahora con los grados con una duración en créditos igual para todas las titulaciones y la excepcional oferta de estudios que

${ }^{20}$ RUBIO LACOBA, M.: "Documentación Informativa en el periodismo digital". Madrid, 2007; pp.106 
hay, nuestra titulación va a tener una fuerte competencia. Además en el momento de decidir los estudios universitarios, a los diecisiete años, uno se guía sobre todo por la imagen social de la carrera y lamentablemente, la nuestra sigue sin tener una imagen profesional fuerte" ${ }^{21}$

El profesor Tejada Artigas aventura: "Cabe la posibilidad de que en los próximos años veamos una desaparición del grado en Información y Documentación, y que nuestra formación se vea únicamente contemplada en los másteres. En muchos países ha ocurrido así. Y esta situación, si logra dar un mayor nivel a nuestra formación, no tendrá porque ser dramática" ${ }^{\prime 2}$. Ni ha de ser dramática ni definitiva, ya que la formación en esas disciplinas siempre ha de existir, bien como grado o titulación, bien como posgrado o especialización.

Los posgrados deberán contar con una formación no sólo basada en la Biblioteconomía, Documentación y Archivística, sino conjunta con otras disciplinas. "Flexibilidad y cooperación con otros campos" como apunta el profesor Tejada. El documentalista de información ha de basarse sobre todo en los principios de la organización del conocimiento sin olvidarse de sus orígenes, la gestión y administración de la colección, sus fundamentos profesionales, sus servicios técnicos, el arte de la referencia y sus servicios a los usuarios. No ha de cerrarse a abarcar otras competencias que le abran muchas puertas.

El periodista se ve inmerso en un proceso ágil y vertiginoso de servir la noticia en el menor tiempo posible. $\mathrm{Y}$ al tener cierto nivel tecnológico, se auto documenta y cree que puede con todo y que sus informaciones van a gozar de un rigor exhaustivo. Y actúa inconscientemente y no se da cuenta que ha de contrastar las fuentes y evitar el subjetivismo de cada una de ellas.

Al relacionar documentación informativa y periodismo de precisión, el profesor José Aquesolo Vegas afirma: "Incluso en el caso de que el periodista sea testigo de un hecho, nunca podrá evitar ver las cosas desde su propio conjunto de prejuicios y conocimientos. El uso de informaciones generales obtenidas de fuentes de información masiva, como las bases de datos, trata de añadir a la interpretación un conjunto de elementos alternativos y de contraste....en alguna medida puede lograr que las fuentes lleguen directamente al redactor". ${ }^{23}$

${ }^{21}$ TEJADA ARTIGAS, CARLOS M., ThinkEPI: "El debate de la formación universitaria en ByD: más allá de Bolonia". (junio 2009).

22 TEJADA ARTIGAS, CARLOS M., ThinkEPI: "El debate de la formación universitaria en ByD: más allá de Bolonia". (junio 2009).

${ }^{23}$ AQUESOLO VEGAS, J.: "De la Documentación informativa al periodismo de precisión", Documentación de las Ciencias de la Información, n 19; Servicio de Publicaciones. Universidad Complutense. Madrid, 1996. 
Pero la auto documentación, tan habitual en la actualidad, confunde al periodista y le impide aparcar sus vivencias y sus sensaciones y convierten su trabajo en un periodismo de sentimiento, alejándolo de la precisión conveniente a la hora de informar. El redactor se relaciona con los sujetos del acontecimiento y se pone, en ocasiones en su lugar impregnándose sin darse cuenta de subjetividad.

El periodismo de precisión y el periodismo de investigación han de estar vinculados a la documentación informativa. Y, estos profesionales, ya compartían labores sin darse cuenta de ello, desde mucho tiempo atrás. Así lo señalaba José Aquesolo Vegas en 1995: "El redactor se acerca al departamento de documentación, tal vez, pero el documentalista puede convertirse en alguna ocasión en redactor de informaciones originales y publicables, más que en elaborador de las anotaciones de referencia que en algunas ocasiones pudiera haber venido encargándose de escribir hasta ahora". 24

El documentalista de información de actualidad desempeña unas tareas complejas de extracción, selección, tratamiento y empaquetado de información que dependen en muchas ocasiones de los medios materiales con los que cuenta. Otro factor que influye decisivamente en esa complejidad es que sirve a multitud de disciplinas y siempre dentro de un ambiente científico. Con la llegada de Internet la información adopta nuevas apariencias, y surge un nuevo espacio de reflexión y acción para la Documentación. El Dr. Antonio García Gutiérrez lo aseguraba de este modo: “crear un espacio de reflexión...significa promover hábitos de investigación en nuestro campo de conocimiento, la necesidad de pensarnos y describir qué rol desempeñamos y qué efectos provocamos" ${ }^{\text {. }}$. Luego, la Universidad debe formar para la sociedad un profesional que use herramientas que construye el informático para poder hacer cumplir la cadena documental: producción, gestión y consumo de información. El camino del documentalista de información está unido al del especialista de la información y depende de los procedimientos y productos que les ofertan.

\section{CONCLUSIONES}

1. Entre periodistas y documentalistas, actualmente, se produce un traspaso de labores: los profesionales cambian las funciones, funden sus misiones: las acti-

${ }^{24}$ AQUESOLO VEGAS, J: "De la Documentación informativa al periodismo de precisión", Documentación de las Ciencias de la Información, n 19; Servicio de Publicaciones. Universidad Complutense. Madrid, 1996.

${ }^{25}$ GARCÍA GUTIÉRREZ, ANTONIO: "Notas sobre procesos reflexivos y funciones en los nuevos especialistas de información: aproximación a los perfiles formativo e investigador". Conferencia inaugural curso académico 2000, Escola de Comunicaçoes e Artes, Universidade de Sao Paulo (28 febrero 2000). Ámbitos, $\mathrm{n}^{\mathrm{o}} 3-4,2^{\circ}$ Semestre 2000 (pp. 33-43). 
vidades que antes realizaban varios profesionales, ahora las efectúa solo uno, $\mathbf{y}$ aumentan sus trabajos: los nuevos medios amplían las tareas para el periodista, que interviene en todo el proceso o por tener que crear una misma información para varios medios digitales.

2. Documentalistas y Periodistas han de aceptar y fomentar la coordinación, como una habilidad mutua y recíproca. Ambos profesionales han de dar ese paso. El periodista ha de conocer la actividad del documentalista y su trabajo, valorarlo, respetarlo y acoplarlo a su trabajo periodístico como una necesidad. Y por otro lado el documentalista tiene que saber las necesidades del informador y ofrecerle todo su material documental que distinga y llene de cualidades su trabajo.

3. Todos los documentalistas llevan dentro de sí la figura del documentalista de información, la solución para acrecentar su campo de acción es no limitar sus competencias a bibliotecas, archivos y centros de documentación, sino incluir en sus funciones la gestión de la información. El documentalista de información ha de trabajar para servir la documentación a los profesionales de la comunicación. Por tanto su formación debe ser específica para ello y ha de prepararse en asignaturas de información de actualidad y conocer los medios y las necesidades previas de los periodistas, para poder desempeñar mejor sus funciones.

4. La barrera entre periodistas y documentalistas existe en cuanto a formación. En lo que se refiere a temores, retos, trabajo desempeñado y capacidad de ambos, se podrían unificar bajo una misma formación: "documentalista de información de actualidad”, y sería conveniente agrupar todos estos trabajos y tareas bajo las Ciencias de la Comunicación, la Información y la Documentación, incluyendo también en estas categorías a Informáticos y Gestores de Contenidos.

\section{BIBLIOGRAFÍA}

AQUESOLO VEGAS, J.: "De la Documentación informativa al periodismo de precisión", Documentación de las Ciencias de la Información, $n^{\circ}$ 19; Servicio de Publicaciones. Universidad Complutense. Madrid, 1996.

BRADSHAW, PAUL: Press Gazette. 2007

http://www.pressgazette.co.uk/story.asp? storycode $=40263$ (consultada junio y julio 2010)

BERGHELLA, VANINA: lapropaladora.com; entrevistada por Ibo, 23 mayo 2010 http://www.re-visto.de

COLL VINENT, ROBERTO: "CIENCIA DOCUMENTAL: Principios y sistemas". Barcelona, Mitre, 1984.

DÍAZ ARIAS, R. 2007: “¿Periodistas?, ¿Documentalistas? Lo importante es el mensaje”. Intervención, 11 diciembre 2007, Seminario de Documentación en los Me- 
dios de Comunicación, Departamento de Biblioteconomía y Documentación Facultad Ciencias de la Información.

FERNÁNDEZ FUENTES, Belén: La Documentación Informativa en el Tratado de Otlet, traité.ppt, Seminario Hispanoamericano, Cáceres, abril 13, 2009.

GARCÍA GUTIÉRREZ, ANTONIO: "Notas sobre procesos reflexivos y funciones en los nuevos especialistas de información: aproximación a los perfiles formativo e investigador". Conferencia inaugural curso académico 2000, Escola de Comunicaçoes e Artes, Universidade de Sao Paulo (28 febrero 2000). Ámbitos, no 3-4, $2^{\circ}$ Semestre 2000 (pp. 33-43).

HERNÁNDEZ PÉREZ, A. Y RODRÍGUEZ MATEOS, D.: "Las nuevas competencias del profesional de la información: del control de documentos a la gestión del conocimiento". Jornadas Españolas de Documentación, Vol. 7, 2000.

MARCOS RECIO, Juan Carlos: El Documentalista de Información Electrónica. Documentación de las Ciencias de la Información, 19. pp. 193-210. ISSN 0210-4210. Madrid, 1996.

MICÓ-SANZ, JOSEP-LLUÍS; MASIP-MASIP, PERE Y GARCÍA-AVILÉS, JOSÉ ALBERTO: EPI, mayo 2009, pp.284-290. "periodistas que ejercen de documentalistas (¿y viceversa?). Nuevas relaciones entre la redacción y el archivo".

ORIHUELA COLLIVA, J.L.: Entrevista, 23 mayo 2007, por Stephanie Falla Aroche en Maestros del Web

PARTAL I MONTESINOS, Vicent: Periodistas y Documentalistas, ¿Dónde está la frontera?.2002.

www.uoc.edu/web/esp/art/uoc/partal0402/partal0402.html (consultada marzo 2010)

POTTER, Deborah: "Manual de Periodismo Independiente".

www.scribd.com/doc/24972790/Manual-de-Periodismo-independiente-by-DeborahPotter (consultada agosto 2010)

ROS-MARTÍN, MARCOS: "El periodista será el bloguer total"; 13 mayo 2010. EL DOCUMENTALISTA ENREDADO. Biblioteconomía, Infonomía, Internet y Nuevas Tecnologías. (Red de blogs. Levante-emv.com)

http://www.documentalistaenredado.net/908/el-periodista-sera-el-bloguer-total/ (consultada octubre 2010)

ROSENSTIEL, TOM. Proyecto para la Excelencia en Periodismo. 2005

RUBIO LACOBA, M.: "Documentación Informativa en el periodismo digital". Madrid, 2007; pp.106

RUBIO LACOBA, MARÍA: "Nuevos tiempos para la documentación informativa en el periodismo digital: viejas y nuevas funciones del servicio de documentación digital". Universidad de Navarra. Comunicación y Sociedad. Volumen XVIII, $\mathrm{n}^{\mathrm{o}} 1$, junio 2005.

www.unav.es/cys/xviiil/proteger/rubio.html (consultada mayo 2010)

SALAVERRÍA, RAMÓN. De la pirámide invertida al hipertexto. Hacia nuevos estándares de redacción para la prensa digital". Publicado en NOVÁTICA (revista Asociación de Técnicos Informática), vol. 142, nov.-dic. 1999, pp. 12-15. 
SALAVERRÍA, R. Y NEGREDO, S. "Periodismo Integrado". Barcelona, Sol.90.Media, 2008. ISBN: 978-84-9820954-9; pp. 151-181.

TEJADA ARTIGAS, CARLOS M., THINKEPI: "El debate de la formación universitaria en ByD: más allá de Bolonia". (junio 2009).

VALLE GASTAMINZA, Félix del: El profesional de la documentación: perfil histórico y formación académica. Tesis doctoral dirigida por José López Yepes, leída el 14 de julio de 1990; 561 p. Universidad Complutense de Madrid. Facultad de Ciencias de la Información. Departamento de Periodismo III (Teoría General de la Información). 